\title{
AUTOGENOUS BONE RING TRANSPLANT VERSUS STICKY BONE IN DEFECTIVE SOCKET AUGMENTATION WITH SIMULTANEOUS IMPLANT PLACEMEN
}

\author{
Abdel Aziz Baiomy Abdullah Baiomy* and Abdelbadia A. Abdelmabood**
}

\begin{abstract}
Aim : This study was designed to evaluate efficacy of autologous concentrated growth factors enriched bone graft matrix (sticky bone) bone versus autogenous chin bone ring in the premolarmolar region with simultaneous implant placement.

Patients and methods: Twenty patients had fresh defective extraction sockets in the mandibular premolar-molar region with severely compromised buccal bone divided randomly into equal groups (in group I; sockets were augmented by sticky bone, and in group II; sockets were augmented by chin bone ring). Then dental implants were placed in the same visit and were covered by collagen membrane in both groups. Clinical and radiographic examinations were done to evaluate the soft tissue, stability of dental implant, crestal bone level, and bone density around dental implants immediate $\left(1^{\text {st }}\right.$ week) postoperatively and at, $3^{\text {rd }}, 6^{\text {th }}, 9^{\text {th }}$, and $12^{\text {th }}$ month postoperatively. All readings were recorded and evaluated statistically.
\end{abstract}

Results: Clinically, group II showed little postoperative complications in comparing group I. in the other side, both groups did not show any statistical significance difference in implant stability and probing pocket depth parameters. Radiographically, group I had highly statistical significance more than group II $(\mathrm{P} \leq 0.001)$ in bone density and marginal bone level parameters along time of study.

Conclusion: Both techniques were successful methods for 3D augmentation of severely defective sockets with immediate placement of dental implant with superiority for autogenous bone ring in aspects of marginal bone level, and density of bone around dental implant.

Keywords: bone ring, sticky bone, defective socket, immediate implant, fibrin glue

\footnotetext{
* Assistant Professor of Oral \& Maxillofacial Surgery, Faculty of Dental Medicine, Al-Azhar University, (Assiut, Boys).
}

** Assistant Professor of Oral \& Maxillofacial Surgery, Faculty of Dental Medicine, Al-Zagazig University 


\section{INTRODUCTION}

One of challenges in dental implantology field is defective socket .Defective sockets resulting from either periodontal disease or surgical trauma during extraction may have an insufficient quantity and quality of bone for successful implant placement. Defective sockets had been classified into four classes according to the degree of severity of the buccal wall defects and they emphasize the effect of the degree of the buccal wall defect and its relationship to implant placement and adjunctive augmentation techniques. Authors concluded that both type I and II defects are suitable for immediate implantation. While, sockets of class III and class IV are severely compromised, with partial or total loss of the buccal plate of bone, and implant placement within the remaining bone would result in a significantly off-axis implant position. Therefore, immediate implantation is impossible ${ }^{1}$.

There are several techniques were developed for the augmentation of defective sockets for implant placement either immediately or after complete bone formation. These include socket preservation, guided bone regeneration, and localized horizontal ridge augmentation using titanium mesh, onlay bone grafting, ridge split technique, and distraction osteogenesis ${ }^{2-7}$.

In order to accelerate healing of bone graft in the bony defect, numerous techniques utilizing platelet and fibrinogen concentrations have been described in the literature ${ }^{8-10}$. Accordingly, several studies used a newly developed autologous concentrated growth factors enriched bone graft matrix (sticky bone)combine with guided tissue regeneration or no to reconstruct bone defect, socket preservation and alveolar ridge augmentation ${ }^{10-14}$. Where, sticky bone has numerous advantages such as 1) it is moldable, so well adapted over various shape of bony defect; 2) Micro and macro movement of grafted bone is prevented. So the volume of augmentation is maintained during healing period, therefore the need of block bone and titanium mesh is minimized;
3) Fibrin network entraps platelets and leukocytes to release growth factors, so bone regeneration and soft tissue is accelerated; 4) No biochemical additives are needed to make sticky bone; 5) Fibrin interconnection minimizes soft tissue ingrowth into the sticky bone graft ${ }^{11,12}$.

This encouraged authors to augment the severely defective socket three-dimensionally with sticky bone with/ without titanium mesh and immediate implant placement in a one-stage procedure to reduce time of treatment ${ }^{12}$. In the same context, a new technique was developed by authors ${ }^{15-18}$ to augment the defective socket with autologous "bone ring" graft harvested from chin with simultaneous implant placement. By this technique, the harvested rings can then be secured to the extraction socket using the dental implants restoring the deficient crestal bone in a three dimensions fashion.

Recently, Chandra et $\mathrm{al}^{19}$ compered between autogenous bone ring transplant versus autologous growth factor- enriched bone graft matrix in extraction socket with deficient buccal bone without simultaneous implant placement and concluded that both techniques were acceptable with superiority for autogenous bone ring transplant. They stated that the main limitation of this study was it did not compare between both in defective socket augmentation with simultaneous implant placement. Accordingly, the present study was atrial to compare between sticky bone and enriched fibrin membrane versus autogenous chin bone ring in management of severely defective sockets before immediate placement dental implant

\section{PATIENT AND METHODS}

A clinical study was conducted on 20 patients systemically healthy patients (6 female and 14 male; mean age $23 \pm 6$ years) with defective sockets requiring extractions and immediate implant placement.All patients were selected from outpatient clinic at the department of Oral and Maxillofacial Surgery, faculty of dental medicine, 


\section{Al-Azhar University, (Assiut, Boys).}

The clinical study extended from March 2016 till March 2019 year. Research procedures were explained to all the patients and they signed an informed consent form before the study. The study was conducted according to rules of ethics declared by Helsinki, and ethical committee approval was obtained from Al-Azhar ethical committee.

\section{Selection criteria:}

-Inclusion criteria: All selected patients had fresh defective extraction sockets in the mandibular premolar- molar region in which the buccal bone was severely compromised and implant placement within the remaining bone would have resulted in a significantly off-axis implant position. All socket had adequate bone at least 3-4 $\mathrm{mm}$ beyond the apex of the tooth to . The alveolar bone surrounding the extraction sockets was defective either due to periodontal disease or traumatic extraction.

-Exclusion criteria: Patients having extraction sockets with no bony defects, medically compromised patients, presence of acute periapical pathology, alcoholics, and tobacco abusers were excluded from the study.

\section{Patient grouping:}

Patients classified randomly into the following two equal groups using online software (https:// www. randomizer.org):

- Group I: included 10 patients with 10 fresh defective extraction sockets in the mandibular premolar- molar region were grafted by sticky bone with immediate implant placement and was covered by collagen membrane

- Group II: included 10 patients with 10 fresh defective extraction sockets in the mandibular premolar- molar region were grafted by autogenous bone ring ,harvested from chin with immediate implant placement and was covered by collagen membrane

\section{Materials:}

- Two-stage screw Superline System of dental implant ( Dentium, Co. Ltd, Suwon, South Korea) was used in the present study. Implant diameter ranged from 3.8 to $4.6 \mathrm{~mm}$ and implant length ranged from 10 to $12 \mathrm{~mm}$.

- The trephine burs utilized in this study were supplied with diameters $6.0 \mathrm{~mm}, 7.0 \mathrm{~mm}, 8.0$ $\mathrm{mm}, 9.0 \mathrm{~mm}$, and $10.0 \mathrm{~mm}$ (Dentium Co., Ltd, Gyeonggi-do, Korea).

- Bone graft was used in sticky bone preparation was Bone Medik-DM ${ }^{\circledR}$ (Bone medic, Metabiomed, Korea), which is resorbable and replaceable by new bone.

- Collagen membrane (GENOSS, Dentium. Co., Ltd , Suwon, South Korea) was used in this study as guider tissue regeneration membrane.

\section{A-Preoperative phase:}

Patients' data were collected and, medical and dental histories were taken. Routine blood investigations were carried out. Also, all patients underwent pre-operative clinical examination and CBCT evaluation to exclude any pathosis , evaluate the dimensions of the socket, amount of augmentation required and to decide the length and diameter of the implant to be used based on the regional anatomy.

\section{Pre-surgical medication:}

One hour before the surgery, each patient was received prophylactic antibiotic, mouth wash, and anti-inflammatory drugs to decrease rate of incidence of infection and edema. They were definitively described in postoperative medications.

\section{Preparation of sticky bone graft ${ }^{(12,13)}$ :}

- $10 \mathrm{~mL}$ of patient's venous blood was taken from the antecubital fossa.

- After that, the blood in the test tubes was centrifuged at $2700 \mathrm{rpm}$ for 2 minutes. The test 
tube showed 2 different layers. The upper layer is autologous fibrin glue (AFG) layer and red blood cell is collected in bottom layer which had been discarded.

- The upper AFG was aspirated by syringe and mixed with particulate bone powder and allowed for 5-10 minutes for polymerization in order to produce sticky bone which has a yellow color

\section{$B$-Operative phase}

- All surgical operations were performed under local anesthesia, articaine HCL and epinephrine 1:20.000 (Septodont, by Novocol Pharmaceutical of Canada, Inc.).

- After standard inferior alveolar nerve block had been administered, the tooth extraction was performed with forceps without distorting or damaging the alveolar bone followed by curettage of any soft and hard tissues debris inside tooth socket.

- All teeth sockets were divided randomly into equal groups as following.

Group I: It included 10 teeth sockets were augmented by bone rings were harvested from chin as following:

- In the chin region, an intraoral unilateral small vestibular incision was made $3 \mathrm{~mm}$ below the attached gingiva. Then the flap was dissected and reflected with partial preservation of the muscle attachment.

- Based on the preoperative CBCT planning, the selected chin area was outlined monocortically with a trephine bur of sequentially larger diameter than that utilized in the preparation of the socket, creating what is called a chin disc.

- An implant osteotomy was performed in the center of this disc utilizing successive drills corresponding to the planned implant length and diameter, with preservation of at least 2 $\mathrm{mm}$ of normal intact bone around the implant osteotomy (fig.1a).
- Harvesting of the bone ring was completed bicortically using the same trephine bur that was used to outline it. The trephine bur was penetrated into the bone, and then smooth cutting was possible. Then bone ring was removed using a bone rasp or a chisel. The harvested ring was kept in normal saline and the flap was closed tightly in layers (fig.1b).

- The customized bone ring was introduced into the prepared defective socket under delicate pressure utilizing a small bone mallet, augmenting it three-dimensionally; the ring was positioned such that it was $1-2 \mathrm{~mm}$ above the adjacent socket walls to compensate for the anticipated bone resorption. After ring placement and immobilization, the final implant drill was introduced through the central osteotomy of the bone ring to prepare the remaining apical bone of the socket for at least $3 \mathrm{~mm}$. The implant was then screwed passively through the tapped central osteotomy of the harvested ring and firmly into the prepared bone apical to the ring using a torque ratchet (fig.1c)

- The platform of the implant was positioned 1 mm below the surface of the ring to compensate for the anticipated crestal bone resorption. Finally, the covering screw was secured and the ring margin was rounded using a small egg shaped bur.

Group II: It included 10 teeth sockets were augmented by sticky bone and immediate implant placement as following:

- A fully-reflected mucoperiosteal flap was made and alveolar ridge was exposed( fig.1d).

- Preparation of the implant site was done using the specific sequence of drills at apical bone of the socket. Drilling has been extended 2 - 3mm apically beyond the apex of the root or the base of the socket to gain primary stability for the implant from the apical bone. Then, endosseous implants were inserted $1 \mathrm{~mm}$ below margins of alveolar sockets ensuring sufficient primary stability . 


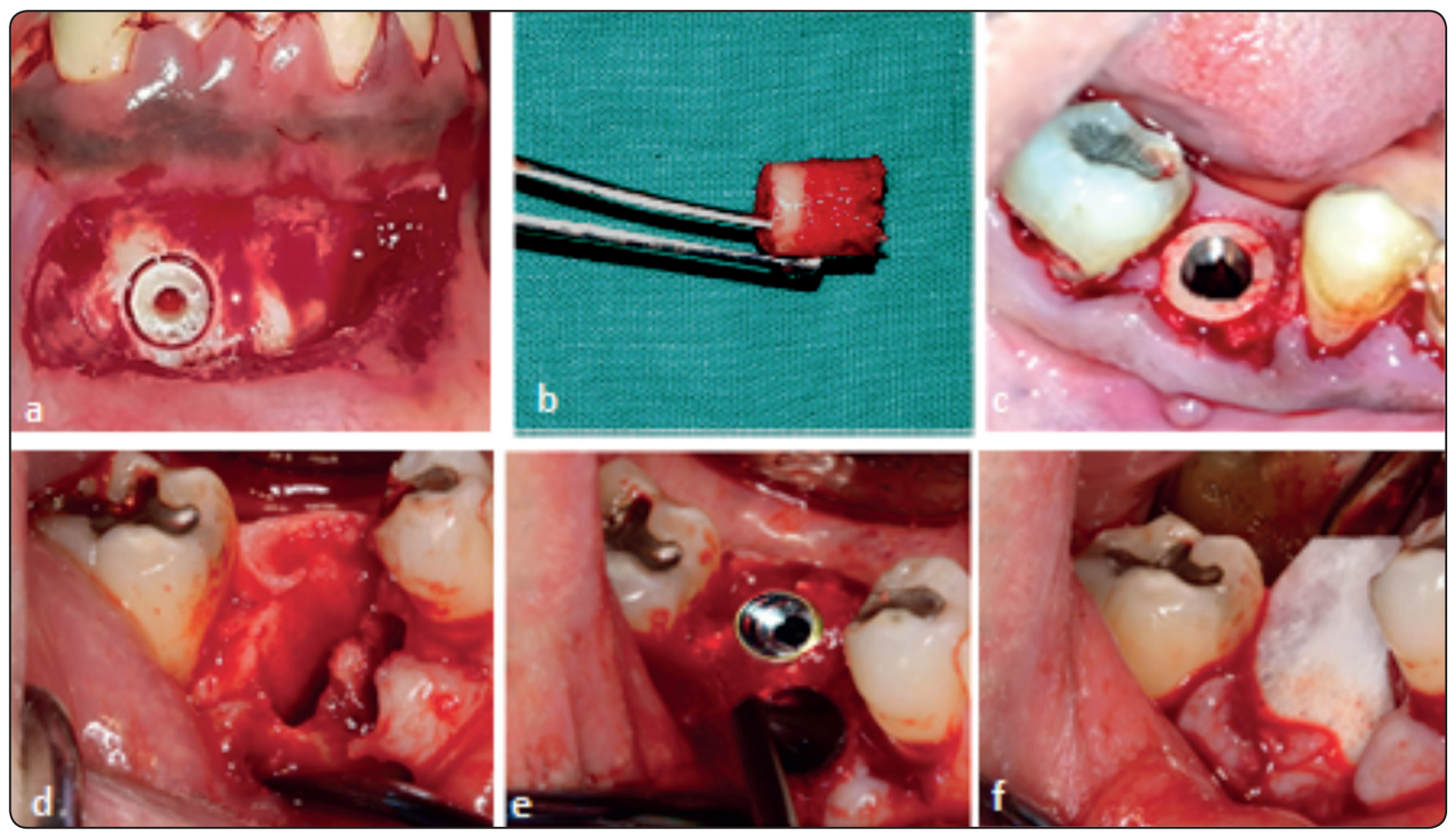

Fig. (1) (a) Marking outline of ring graft using trephine bur and preparation of implant site on graft (b) Harvested graft (c) Placement of bone ring and implant through it in group I (d) defective socket after extraction in group II (e) Immediate implant placement and packing sticky bone graft around implant in defective socket (f) Placement of collagen membrane after implant placement and socket augmentation.

- The covering screw was secured and the alveolar margins of socket were rounded using a small egg shaped bur to remove any sharp edges .Then, prepared sticky bone was over packed around dental implant inside socket, and at buccal aspect (fig.1e).

In all groups, bone augmentation and immediate implant placement followed by placement of GTR membrane, and the flap was relaxed through scoring of the periosteum and then advanced and closed by interrupted suturing (fig.1f).

- In all groups, prosthetic phase was performed at 6 month postoperatively .

\section{C-Postoperative phase}

In group I, after closure of the wound, a pressure band was applied to the chin and cheek areas for 48 $\mathrm{h}$ postoperatively. The patients were then instructed to apply ice-packs over the chin and cheek area for $20 \mathrm{~min}$ every hour for $6 \mathrm{~h}$ postoperatively.
All patients in groups were instructed to keep on a soft diet for the first 48 hours, and rinse their mouth with chlorhexidine mouth wash (DG-wash, Al Esraa Pharmaceuticals, Fourth Industrial Zone, Badr Industrial City, Cairo, Egypt.) starting on the second day after surgery, three times per day during the first week postoperative. Amoxicillin 875 $\mathrm{mg} /$ claviulanic acid $125 \mathrm{mg}$ antibiotic tablet (Augmentin $1 \mathrm{gm}$, Glaxosmithkline, Australia) was prescribed as one tablet every 12 hours for seven days postoperatively. Diclofenac sodium non-steroidal anti-inflammatory drugs $75 \mathrm{mg}$ tabs (Cataflam, Novartis pharma, Basel, Switzerland) was prescribed to be used one tablet every 8 hours for seven days. Chymotrypsin + trypsin ${ }^{\circledR}$ tablets (Alphintern, Kahira. pharm \& chem. Ind. co., Cairo, Egypt), was administrated half an hour before meals 3 times for seven days. 


\section{D- Follow up phase}

\section{Clinical evaluation}

Early follow up was performed daily for the first first month for any signs of infection, pain, swelling or any post-operative complications.

- Probing Depth (PD): It was measured as the distance from the crest of gingival margin to the bottom of the gingival sulcus at four sites around implants using a Williams probe.

- Changes in Implant Stability Quotient (ISQ): Changes in implant stability quotient (ISQ): By using Osstell, (Osstell AB Stampgatan 14, Goteborg, Sweden) primary stability was recorded immediately after implant placement and at 6 months for each implant.

\section{Radiographic Evaluation:}

During the follow-up period, CBCT scans were obtained immediately (within 1 week) ,3 6, and 12 months postoperative for the measurement of crestal bone loss, bone density at bone graft implant interface,

\section{- Measuring the crestal bone height:}

In the coronal section, a straight line was drawn just parallel to the implant long axis week after implant placement, then weekly for the

from the buccal marginal bone level around dental implant to the point of intersection with the axial orientation axis and perpendicular to it. The height obtained was recorded in millimetres. The same process was repeated for the lingual side.

In the sagittal section, a straight line was drawn just parallel to the implant long axis from the mesial marginal bone level around dental implant to the point of intersection with the axial orientation axis and perpendicular to it. The height obtained was recorded in millimetres. The same process was repeated for the distal side ( fig. $2 \& 3$ )

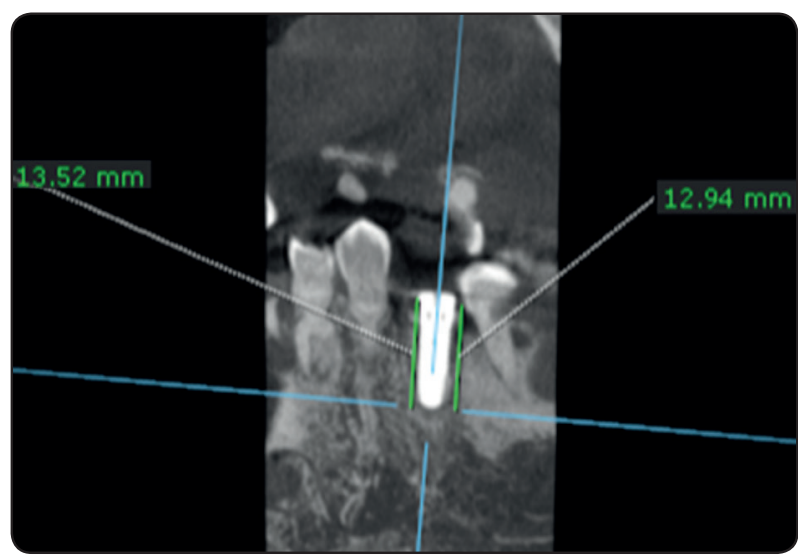

Fig. (2) Postoperative CBCT showing assessment of height of bone in the sagittal slice.

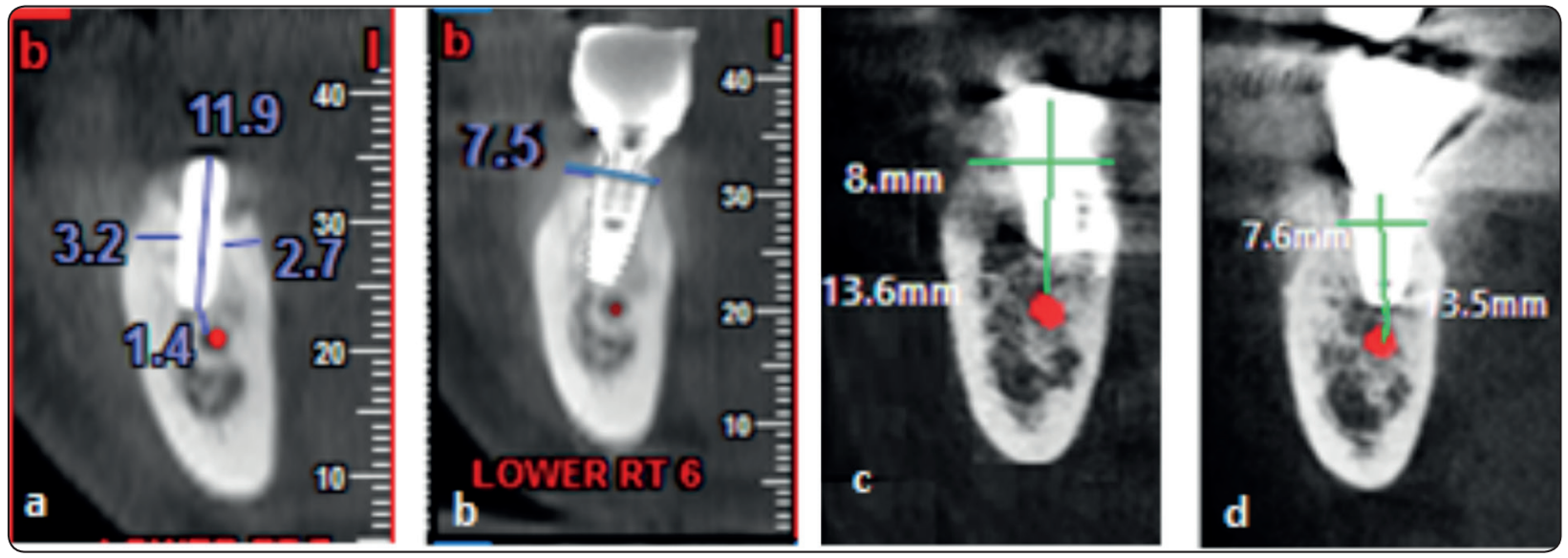

Fig. (3) Coronal cuts of CBCT showing measurements of alveolar ridge width in group I immediately (a) and at12 month (b) \& group II immediately (c) and at 12 month (d). 


\section{- Measuring bone density}

In the coronal section, a straight line was drawn just parallel to the implant from the buccal marginal bone around implant to the apical end of implant; the mean bone density obtained was recorded in HU (making use of the ROI tool present in the software). The same process was repeated for the lingual side.

In the sagittal section, a straight line was drawn just parallel to the implant from the mesial marginal bone around implant to the apical end of implant; the mean bone density obtained was recorded in HU (making use of the ROI tool present in the software). The same process was repeated for the distal side. After this, the average of bone density around dental implant was calculated.

\section{Statistical analysis}

The data were collected, tabulated and statistically analysed by Statistical Package for Social Sciences (SPSS) version 25. Descriptive statistics and frequency distribution were analyzed. Intergroup comparison was done using an unpaired t test. A paired $t$ test was used for comparison inside groups. $\mathrm{P} \leq 0.05$ was considered statistically significant, and $\mathrm{P} \leq 0.001$ was considered highly significant. Graphs were performed using the Microsoft Excel 2019 program.

\section{RESULTS}

\section{Clinical results}

This study included a total of 20 patients. All patients selected had severely defective extraction sockets in the mandibular premolar-molar region (eight premolars, and twelve molars). All patients had complete implant osseointegration without any failure up to last interval of study except, one case in group I whom was replaced by another one. Group
I included six rings were harvested using a $7.5 \mathrm{~mm}$ diameter trephine and four rings using a $10 \mathrm{~mm}$ diameter trephine. In rings with $7.5 \mathrm{~mm}$ diameter, internal osteotomy diameter was $3.75 \mathrm{~mm}$ while in rings with $10 \mathrm{~mm}$ diameter, internal osteotomy was $4.2 \mathrm{~mm}$. In Group II dental implants lengths ranged from 10 to $12 \mathrm{~mm}$ and their width measurements ranged from 3.6 to $4.2 \mathrm{~mm}$.

All patients had optimal wound healing without any infection, dehiscence. Except, one patient in group I had soft tissue dehiscence of bone ring graft at implant site at 1-week follow-up. Which healed spontaneously by secondary intention after smoothing sharp edges and using chlorhexidine mouth wash. Mild postoperative oedema was noted next day after surgery in all patients, which had resolved completely at postoperative 1 week in group I and after 3-4 days in group II.

Regards to loss of nerve sensation, all patients did not have any loss of sensation at implant site or donor site. Except, three patients of group I suffered from transient numbness of the lower lip, which disappeared by the fourth to eight week postoperatively.

\section{Changes in Probing Depth measurement (PD)}

Probing depth measurements were decreased gradually by the end of study in all groups. The mean value of probing depth in group I was 3.64 $\mathrm{mm} \pm 0.410$ at base line that reduced to $1.75 \mathrm{~mm}$ \pm 0.23 after 12 months. The mean value of probing depth in group II was $3.45 \mathrm{~mm} \pm 0.80$ at base line that reduced to $2.28 \mathrm{~mm} \pm 0.21$ after 12 months. Pairedtest showed highly statistical significant difference at all intervals when compared to baseline in group I and at 12 month only when compared to baseline in group II. While, an unpaired test showed no statistical significant difference between groups at all intervals (table 1). 
TABLE (1): Mean \pm SD values of Probing depth (PD) among studied groups at each evaluation period, along with significance level using paired \& unpaired t-test.

\begin{tabular}{|c|c|c|c|c|c|c|c|c|c|c|c|c|}
\hline \multicolumn{3}{|c|}{ Follow Up Periods } & \multicolumn{2}{|c|}{ Baseline } & \multicolumn{2}{|c|}{3 Month } & \multicolumn{2}{|c|}{6 Month } & \multicolumn{2}{|c|}{9 Month } & \multicolumn{2}{|c|}{12 Month } \\
\hline \multicolumn{3}{|c|}{ Studied Groups } & \multicolumn{2}{|c|}{ Mean \pm SD } & \multicolumn{2}{|c|}{ Mean \pm SD } & \multicolumn{2}{|c|}{ Mean \pm SD } & \multicolumn{2}{|c|}{ Mean \pm SD } & \multicolumn{2}{|c|}{ Mean \pm SD } \\
\hline \multicolumn{3}{|c|}{ Group I } & \multicolumn{2}{|c|}{$3.64 \pm 0.410$} & \multicolumn{2}{|c|}{$3.33 \pm 0.32$} & \multicolumn{2}{|c|}{$2.85 \pm 0.42$} & \multicolumn{2}{|c|}{$2.49 \pm 0.36$} & \multicolumn{2}{|c|}{$1.75 \pm 0.23$} \\
\hline \multicolumn{2}{|c|}{ Group II } & & \multicolumn{2}{|c|}{$3.45 \pm 0.80$} & \multicolumn{2}{|c|}{$3.24 \pm 0.70$} & \multicolumn{2}{|c|}{$2.94 \pm 0.54$} & \multicolumn{2}{|c|}{$2.68 \pm 0.47$} & \multicolumn{2}{|c|}{$2.28 \pm 0.21$} \\
\hline \multicolumn{13}{|c|}{ Unpaired t-Test } \\
\hline & & \multicolumn{2}{|c|}{$\mathbf{t}$} & & $\mathbf{t}$ & $\mathbf{p}$ & $\mathbf{t}$ & $\mathbf{p}$ & $\mathbf{t}$ & $\mathbf{P}$ & $\mathbf{t}$ & $\mathbf{p}$ \\
\hline G I & Vs G II & \multicolumn{2}{|c|}{0.661} & & 0.386 & 0.704 & 0.386 & 0.706 & 0.319 & 0.753 & 1.03 & 0.32 \\
\hline \multicolumn{13}{|c|}{ Paired $t$-Test } \\
\hline & \multicolumn{2}{|c|}{3 month VS. baseline } & \multicolumn{3}{|c|}{6 month VS. baseline } & \multicolumn{4}{|c|}{9 month VS. baseline } & \multicolumn{3}{|c|}{12 month VS. baseline } \\
\hline & $\mathbf{t}$ & $\mathbf{P}$ & \multicolumn{2}{|c|}{$\mathbf{t}$} & $\mathbf{P}$ & \multicolumn{2}{|r|}{$\mathbf{t}$} & \multicolumn{2}{|c|}{$\mathbf{p}$} & $\mathbf{t}$ & \multicolumn{2}{|c|}{$\mathbf{p}$} \\
\hline Group I & 4.12 & $0.003^{* *}$ & & & $<0.001 *$ & & 10.90 & $<0.0$ & $1^{* *}$ & 16.69 & & $001^{* *}$ \\
\hline Group II & 0.958 & 0.363 & & & $0.04^{*}$ & & 3.272 & 0.0 & & 4.70 & & $01^{* *}$ \\
\hline
\end{tabular}

*Statistically significant: $(P<0.05)$

**High statistically significant: $(P<0.01)$.

Changes in Implant Stability Quotient (ISQ):

ISQ values were decreased at 6 month observation interval in all groups. The mean value of ISQ in group I was $68.45 \pm 5.22$ at baseline that decreased to $64.73 \pm 5.83$ after 6 months. The mean value of ISQ in group II was $69.00 \pm 3.03$ at baseline that decreased to $66.55 \pm 2.66$ after 6 months. In both groups, Paired t-test showed high statistical significant difference at 6 month observation interval when compared to baseline observation period. However, there was no statistical significant difference between both groups (table 2).

TABLE (2): Mean \pm SD values of ISQ scores among studied groups at two evaluation periods, along with significance level using paired \& unpaired t-test.

\begin{tabular}{|c|c|c|c|c|c|c|}
\hline Follow Up Periods & \multirow{2}{*}{\multicolumn{2}{|c|}{$\begin{array}{c}\text { Baseline } \\
\text { Mean士 SD }\end{array}$}} & \multirow{2}{*}{\multicolumn{2}{|c|}{$\begin{array}{c}6 \text { Month } \\
\text { Mean } \pm \text { SD }\end{array}$}} & \multicolumn{2}{|c|}{ Baseline VS. 6 Month } \\
\hline Studied Groups & & & & & $\mathbf{t}$ & $\mathbf{p}$ \\
\hline Group I & & & & & 7.11 & $0.0001 * *$ \\
\hline \multirow[t]{2}{*}{ Group II } & \multicolumn{2}{|c|}{$69.00 \pm 3.03$} & \multicolumn{2}{|c|}{$66.55 \pm 2.66$} & 3.61 & $0.004 * *$ \\
\hline & $\mathbf{t}$ & $\mathbf{P}$ & $\mathbf{t}$ & $\mathbf{p}$ & & \\
\hline G I Vs G II & 0.30 & 0.765 & 0.94 & 0.357 & & \\
\hline
\end{tabular}




\section{Changes in Marginal bone level (MBL)}

MBL was decreased gradually by the end of study in all groups. Where, the mean value of MBL in group I was $4.04 \mathrm{~mm} \pm 0.360$ at base line that reduced to $2.04 \mathrm{~mm} \pm 0.05$ after 12 months. The mean value of MBL in group II was $4.26 \mathrm{~mm}$ \pm 0.27 at base line that reduced to $2.57 \mathrm{~mm} \pm$ 0.18 after 12 months. Paired-test showed highly statistical significant difference at all intervals when compared to baseline in both groups. Also, unpaired test showed highly statistical significant difference between groups at all intervals except at baseline. Where, MBL measurements were higher in group II than group I at 3, 6, 9, and 12 month intervals illustrating more bone resorption in group II than group I (table 3).

\section{Changes in Bone Density Measurements (BD):}

BD measurements as in table 4 showed gradual elevation during observation period of the study. In group I, the mean value of bone density at base line was $541.8 \mathrm{HU} \pm 125.82$ that elevated to $1538.9 \mathrm{HU}$ \pm 182.68 at 12 months after implant placement. In group II , the mean value of bone density at base line was $494.20 \mathrm{HU} \pm 116.42$ that elevated to1382.4 $\mathrm{HU} \pm 154.27$ at 12 months of implant placement .The difference within the groups was highly statistical significant at 3, 6, 9 and 12 months when compared with base line. Unpaired-test for comparing bone density between the two groups showed statistical significant difference at 3 month and highly statistical significant difference at 6, 9, and 12 intervals of the study with superiority for group I in BD values.

TABLE (3): Mean \pm SD values of Marginal Bone level among studied groups at each evaluation period, along with Significance level using paired \& unpaired t-test.

\begin{tabular}{|c|c|c|c|c|c|c|c|c|c|c|c|c|}
\hline \multicolumn{3}{|c|}{ Follow Up Periods } & \multicolumn{2}{|c|}{ Baseline } & \multicolumn{2}{|c|}{3 Month } & \multicolumn{2}{|c|}{6 Month } & \multicolumn{2}{|c|}{9 Month } & \multicolumn{2}{|c|}{12 Month } \\
\hline \multicolumn{3}{|c|}{ Studied Groups } & \multicolumn{2}{|c|}{ Mean \pm SD } & \multicolumn{2}{|c|}{ Mean \pm SD } & \multicolumn{2}{|c|}{ Mean \pm SD } & \multicolumn{2}{|c|}{ Mean \pm SD } & \multicolumn{2}{|c|}{ Mean \pm SD } \\
\hline \multicolumn{3}{|c|}{ Group I } & \multicolumn{2}{|c|}{$4.04 \pm 0.36$} & \multicolumn{2}{|c|}{$2.95 \pm 0.21$} & \multicolumn{2}{|c|}{$2.40 \pm 0.25$} & \multicolumn{2}{|c|}{$2.17 \pm 0.12$} & \multicolumn{2}{|c|}{$2.04 \pm 0.05$} \\
\hline \multicolumn{3}{|c|}{ Group II } & \multicolumn{2}{|c|}{$4.26 \pm 0.27$} & \multicolumn{2}{|c|}{$3.85 \pm 0.23$} & \multicolumn{2}{|c|}{$3.54 \pm 0.26$} & \multicolumn{2}{|c|}{$3.21 \pm 0.17$} & \multicolumn{2}{|c|}{$2.48 \pm 0.21$} \\
\hline \multicolumn{13}{|c|}{ Unpaired t-Test } \\
\hline & & $\mathbf{T}$ & $\mathbf{p}$ & $\mathbf{t}$ & $\mathbf{P}$ & \multicolumn{2}{|c|}{$\mathbf{t}$} & 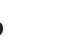 & $\mathbf{T}$ & $\mathbf{P}$ & $\mathbf{t}$ & $\mathbf{P}$ \\
\hline \multicolumn{2}{|c|}{ G I Vs G II } & 1.66 & 0.1 & 8.38 & $<0.001^{* *}$ & \multicolumn{2}{|c|}{9.31} & $<0.001^{* *}$ & 13.31 & $<0.001^{* *}$ & 8.49 & $<0.001^{* *}$ \\
\hline \multicolumn{13}{|c|}{ Paired $t$-Test } \\
\hline & \multicolumn{3}{|c|}{3 month VS. baseline } & \multicolumn{2}{|c|}{6 month VS. baseline } & \multicolumn{4}{|c|}{9 month VS. baseline } & \multicolumn{3}{|c|}{12 month VS. baseline } \\
\hline & $\mathbf{t}$ & & & $\mathbf{t}$ & $\mathbf{P}$ & & & & ? & $\mathbf{t}$ & & $\mathbf{P}$ \\
\hline G I & 9.12 & $<0$. & & 11.29 & $<0.001^{* *}$ & & & $<0$ & $001^{* *}$ & 21.69 & & $<0.001^{* *}$ \\
\hline G II & 8.49 & $<0$. & & 7.20 & $<0.001^{* * *}$ & & & $<0$ & $01^{* *}$ & 9.17 & & $<0.001^{* *}$ \\
\hline
\end{tabular}

*Statistically significant: $(P<0.05)$

**High statistically significant: $(P<0.01)$. 
TABLE (4): Mean \pm SD values of Bone density (HU) among groups at each evaluation period, along with Significance level using paired \& unpaired t-test.

\begin{tabular}{|c|c|c|c|c|c|c|c|c|c|c|c|}
\hline \multicolumn{2}{|c|}{ Follow Up Periods } & \multicolumn{2}{|c|}{ Baseline } & \multicolumn{2}{|c|}{3 Month } & \multicolumn{2}{|c|}{6 Month } & \multicolumn{2}{|c|}{9 Month } & \multicolumn{2}{|c|}{12 Month } \\
\hline \multicolumn{2}{|c|}{ Studied Groups } & \multicolumn{2}{|c|}{ Mean \pm SD } & \multicolumn{2}{|c|}{ Mean \pm SD } & \multicolumn{2}{|c|}{ Mean \pm SD } & \multicolumn{2}{|c|}{ Mean \pm SD } & \multicolumn{2}{|c|}{ Mean \pm SD } \\
\hline \multicolumn{2}{|c|}{ Group I } & \multicolumn{2}{|c|}{$541.82 \pm 125.82$} & \multicolumn{2}{|c|}{$756.01 \pm 89.25$} & \multicolumn{2}{|c|}{$955.84 \pm 134.2$} & \multicolumn{2}{|c|}{$1371.17 \pm 172.12$} & \multicolumn{2}{|c|}{$1538.9 \pm 182.68$} \\
\hline \multicolumn{2}{|c|}{ Group II } & \multicolumn{2}{|c|}{$494.20 \pm 116.42$} & \multicolumn{2}{|c|}{$634.95 \pm 193.21$} & \multicolumn{2}{|c|}{$857.52 \pm 112.26$} & \multicolumn{2}{|c|}{$1205.21 \pm 90.17$} & \multicolumn{2}{|c|}{$1382.4 \pm 154.27$} \\
\hline \multicolumn{12}{|c|}{ Unpaired t-Test } \\
\hline & & $\mathbf{t}$ & $\mathbf{p}$ & $\mathbf{t}$ & $\mathbf{P}$ & $\mathbf{t}$ & $\mathbf{p}$ & $\mathbf{t}$ & $\mathbf{P}$ & $\mathbf{t}$ & $\mathbf{P}$ \\
\hline \multicolumn{2}{|c|}{ G I Vs G II } & 1.22 & 0.235 & 2.693 & $0.01 *$ & 4.27 & $0.000 * *$ & 5.25 & $0.000 * *$ & 5.54 & $0.000 * *$ \\
\hline \multicolumn{12}{|c|}{ Paired $t$-Test } \\
\hline & \multicolumn{2}{|c|}{3 month Vs. baseline } & \multicolumn{3}{|c|}{6 month Vs. baseline } & \multicolumn{3}{|c|}{9 month Vs. baseline } & \multicolumn{3}{|c|}{12 month Vs. baseline } \\
\hline & $\mathbf{t}$ & $\mathbf{P}$ & $\mathbf{t}$ & \multicolumn{2}{|c|}{$\mathbf{P}$} & \multicolumn{2}{|l|}{$\mathbf{t}$} & $\mathbf{p}$ & $\mathbf{t}$ & \multicolumn{2}{|c|}{$\mathbf{P}$} \\
\hline G I & 0.987 & 0.349 & 6.09 & \multicolumn{2}{|c|}{$0.000 * *$} & \multicolumn{2}{|c|}{9.212} & $0.000 * *$ & 9.320 & & $.000 * *$ \\
\hline G II & 6.40 & $0.000 * *$ & 12.31 & 0.00 & & 16.9 & & $0.000 * *$ & 14.78 & & $.000 * *$ \\
\hline
\end{tabular}

*Statistically significant: $(P<0.05)$

**High statistically significant: $(P<0.01)$.

\section{DISCUSSION}

One of long term problems after tooth extraction is subsequent bone resorption. Mostly, following extraction, subsequent bone resorption of alveolar ridge may result in a loss of height as well as up to $50 \%$ of width that might negate the placement of dental implants ${ }^{(21)}$. To overcome this drawback, immediate placement protocol was introduced where the implant is installed in conjunction with tooth extraction. (22) However, defective sockets resulting from either periodontal disease or surgical trauma during extraction may have an insufficient quantity of bone for successful implant placement. Several classification systems have been proposed for classifying such defects ${ }^{(1,23,24)}$.

Several approaches ${ }^{(25,26)}$ reported in the literature to reduce the overall treatment time and difficulties in the management of severely defective sockets, through three-dimensionally augmentation of defective socket with autologous "bone rings" and immediate implant placement in a onestage procedure. Recently, some authors ${ }^{(19)}$ used sticky bone with implant placement in two stages procedures for defective socket augmentation to benefit from regenerative properties of autologous fibrin glue.

Our comparative study was conducted with the purpose of evaluating the effectiveness of autologous bone ring versus sticky bone graft as augmentation techniques for the immediate implant placement in defective sockets. All autologous bone ring grafts were harvested from symphysis region. This is in accordance with Misch et $\mathrm{al}^{(27)}$, and Giraddi et al ${ }^{(26)}$.

In the current study, vestibular degloving incision was preferred as it leads to prevent marginal bone loss and esthetic problems with associated gingival recession. This matched with Gapski et al ${ }^{(28)}$ who preferred vestibular incision design than sulcular incision. 
Although, various complications are reported in the literature with the use of vestibular degloving incision for bone ring harvesting such as temporary mental nerve paresthesia, lip ptosis, wound dehiscence, and nonvitality of lower incisors. Our study showed little complications that resolved in short time. Explanation of that is because incision was given unilaterally at least $1 \mathrm{~cm}$ away from the mucogingival junction. Furthermore, incision was not extended beyond canine region and a pressure dressing was applied postoperatively. This is in the same side with Giraddi et al (26) and Gapski et $\mathrm{al}^{(28)}$.Chandra et $\mathrm{al}^{(19)}$ reported absence of any complications with sticky bone versus autologous bone ring in augmentation of defective socket . This is matched with our study.

In our study, all implants in both groups showed adequate primary stability as measured clinically. This is the basic criteria for success of immediate implants and bone grafting. This is in accordance with Ramp et $\mathrm{al}^{(29)}$ and $\mathrm{Su}$ et $\mathrm{al}^{(30)}$ studies and in contrast with Salama et al (1) who reported that implants could not be placed in severely defective sockets because absence initial stability . In our study initial stability was gaited from insertion implant in at least $2 \mathrm{~mm}$ in base of socket.

In the current study, all sockets was covered with GTR membrane after bone grafting and implant insertion to benefit from advantages which demonstrated by Dimitriou et al ${ }^{(31)}$ study such as prevention of the apical migration of epithelium and support new connective tissue attachment and tissue regeneration .

Our results of Implant Stability Quotient showed no statistical significant difference between both groups along time of study. This matched with results of Giraddi et al ${ }^{(26)}$ on bone ring, who explain the stability to the good bone remodeling and osteoconductivity of autogenous graft. Also, our results in agreement with Sohn et al ${ }^{(12)}$,who concluded utilizing of sticky bone in defective socket augmentation to benefit better growth factor release and acceleration of bone healing. In contrast to our results, results of Chandra et al ${ }^{(19)}$ study showed significantly higher stability in sites treated with autogenous bone ring over sites treated with sticky bone. Explanation of that, in our study implant insertion occurred immediately with sticky bone grafting. Sticky bone contains high concentration of growth factors lead to increase the quality of the newly formed bone implant and enhance the rate of osseointegration .This in agreement with Ozemir et $\mathrm{al}^{(32)}$ explanation.

In the present study, the radiographic evaluation demonstrated MBL measurements were higher in group II than group I at 3, 6, 9, and 12 month intervals illustrating more bone resorption in group II than group I. Regarding bone density, there was statistical significant difference at 3 month and highly statistical significant difference at 6, 9, and 12 intervals of the study with superiority for group I in $\mathrm{BD}$ values. These results in agreement with results of Chandra et $\mathrm{al}^{(19)}$ and Omara et $\mathrm{al}^{(16)}$ studies . They explained success of bone ring with immediate implant placement because rapid angiogenesis, with subsequent consolidation of the bone ring into the adjacent alveolar bone and integration of the installed implant into the healed ring.

\section{CONCLUSION}

Both techniques were successful methods for 3D augmentation of severely defective sockets with immediate placement of dental implant. Although autogenous bone ring has some postoperative complications, it was better than sticky bone in aspects of sufficient bone height and quality of bone around dental implant.

Funding: no funding

\section{Conflicts of interest}

There are no conflicts of interest 


\section{REFERENCES}

1. Salama H, Salama M. The role of orthodontic extrusive remodeling in the enhancement of soft and hard tissue profiles prior to implant placement: a systematic approach to the management of extraction site defects. Int J Periodontics Restorative Dent 1993;13: 312-33.

2. Kaufman E, Wang PD. Localized vertical maxillary ridge augmentation using symphyseal bone cores: a technique and case report. Int J Oral Maxillofac Implants 2003;18: 293-8.

3. McAllister B and Haghighat K, Bone augmentation techniques. J. Periodontol. 2007;78, 377- 83 .

4. Buser D, Dula K, Hirt HP, Schenk RK. Lateral ridge augmentation using autograft and barrier membranes: a clinical study with 40 partially edentulous patients. J Oral Maxillofac Surg 1996;54:420-32.

5. Basa S, Varol A, Turker N. Alternative bone expansion technique for immediate implant placement of implants in the edentulous posterior mandibular ridge: a clinical report. Int J Oral Maxillofac Implants 2004;19: 554-8.

6. Anitua E., et al. "The effects of PRGF on bone regeneration and on titanium implant osseointegration in goats: a histologic and histomorphometric study". J Biomed Mater Res 2009; A 91.1 : 158-65.

7. McAllister BS, Haghighat K. Bone augmentation techniques. J Periodontol 2007;78:377-96.

8. Plachokova AS., et al. "Effect of platelet-rich plasma on bone regeneration in dentistry: a systematic review". Clin Oral Impl Res 2008; 19: 539-45.

9. Dohan DM., et al. "Platelet-rich fibrin (PRF): a secondgeneration platelet concentrate. Part I: technological concepts and evolution". Oral Surg Oral Med Oral Pathol Oral Radiol Endod 2006;3 : 37-44.

10. Rodella LF., et al. "Growth factors, CD34 positive cells, and fibrin network analysis in concentrated growth factors fraction”. Microscopy Research and Technique 2011; 74:72-7.

11. Sohn DS, Lecture titled with sinus and ridge augmentation with CGF and AFG, Symposium on CGF and AFG, Tokyo, June 6, 2010

12. Sohn S, Huang B, Kim J, Park E, Park C. Utilization of Autologous Concentrated Growth Factors (CGF) Enriched Bone Graft Matrix (Sticky Bone) and CGF-Enriched Fibrin Membrane in Implant Dentistry. JIACD,2015;7(10);11-29.
13. Waleed M., Abdel Aziz F., Lydia N. Sticky bone in dehiscence defect around dental implant. ADJ 2018;43 :35-40.

14. EL Moheb Mohamed. "The Use of Growth Factors Fibrin Network to Enhance Architecture, Mechanical and Biological Aspect of the Graft Particles". Int J Preven \& Clin Dent Res 2014;1 : 41-4.

15. Nakahara K, Haga-Tsujimura M, Sawada K, Kobayashi E, Mottini M, Schaller B, and Saulacic N. Single-staged versus two staged implant placement using bone ring technique in vertically deficient alveolar ridges-Part 1: Histomorphometric and micro-CT analysis. Clin Oral Implants Res. 2016;27, $1384-9$.

16. Omara M, Abdelwahed N, Ahmed M, and Hindy M. Simultaneous implant placement with ridge augmentation using an autogenous bone ring transplant. Int. J. Oral Maxillofac Surg. 2016;45: 535 -45.

17. Giraddi GB, Saif AM. Bone ring augmentation around immediate implants: A clinical and radiographic study. Ann Maxillofac Surg 2017;7:92-7.

18. Ahmed M Badr., Amal A AL Hessy and Sahar M Ghoraba. "Randomized Controlled Clinical Study of Immediate Implant Placement with Simultaneous Augmentation Using Autogenous versus Xenogenic Ring Block Graft for Periodontally Hopeless Teeth". EC Dental Science 2019;18: 1232-40

19. Chandra R, Shivateja K, Reddy A. autogenous bone ring transplants vs autologous growth factors-enriched bone graft matrix in extraction sockets with deficient buccal bone : Acomparative clinical study.int j oral maxillofac implants2019;34(6),1424-33

20. Schropp L, Wenzel A, Kostopoulos L, Karring T. Bone healing and soft tissue contour changes following single-tooth extraction: A clinical and radiographic 12-month prospective study. Int J Periodontics Restorative Dent 2003; 23:313-23.

21. Vandeweghe S, Hattingh A, Wennerberg A, Bruyn HD. Surgical protocol and short-term clinical outcome of immediate placement in molar extraction sockets using a wide body implants. J Oral Maxillofac Res 2011;2:e1

22. Bhola M, Neely AL, Kolhatkar S. Immediate implant placement: Clinical decisions, advantages, and disadvantages. J Prosthodont 2008; 17:576-81.

23. Juodzbalys G, Sakavicius D, Wang HL. Classifcation of extraction sockets based upon soft and hard tissue components. J Periodontol 2008;79:413-24. 
24. Caplanis N, Lozada JL, Kan JY. Extraction defect assessment, classification, and management. J Calif Dent Assoc 2005; 33:853-63.

25. Stevens MR, Emam HA, Alaily ME, Sharawy M. Implant bone rings. One-stage three-dimensional bone transplant technique: A case report. J Oral Implantol 2010;36:69-74.

26. Giraddi GB, Saif AM. Bone ring augmentation around immediate implants: A clinical and radiographic study. Ann Maxillofac Surg 2017;7:92-7.

27. Misch CM, Misch CE, Resnik RR, Ismail YH. Reconstruction of maxillary alveolar defects with mandibular symphysis grafts for dental implants: A preliminary procedural report. Int J Oral Maxillofac Implants 1992;7:360-6

28. Gapski R, Wang HL, Misch CE. Management of incision design in symphysis graft procedures: A review of the literature. J Oral Implantol 2001; 27:134-42.
29. Ramp LC, Jeffcoat RL. Dynamic behavior of implants as a measure of osseointegration. Int J Oral Maxillofac Implants 2001;16:637-45.

30. Su CY, Kuo YP, Tseng YH, Su CH, Burnouf T. In vitro release of growth factors from platelet-rich fbrin (PRF): A proposal to optimizethe clinical applications of PRF. Oral Surg Oral Med Oral Pathol Oral Radiol Endod 2009;108:56-61.

31. Dimitriou R, Mataliotakis G, Maria G, Giannoudis C . The role of barrier membranes for guided bone regeneration and restoration of large bone defects: current experimental and clinical evidence. BMC Medicine 2012;10:81-9.

32. Ozdemir H, Ezirganli S, Isa Kara M, Mihmanli A, Baris E. Effects of platelet rich fibrin alone used with rigid titanium barriers. Arch Oral Biol. 2013;58:537-44. 